This item was submitted to Loughborough's Research Repository by the author.

Items in Figshare are protected by copyright, with all rights reserved, unless otherwise indicated.

\title{
Sedentary behaviour and diet across the lifespan: an updated systematic review
}

PLEASE CITE THE PUBLISHED VERSION

http://dx.doi.org/10.1136/bjsports-2014-093754

\section{PUBLISHER}

(CThe Authors. Published by the BMJ Publishing Group

VERSION

SMUR (Submitted Manuscript Under Review)

\section{PUBLISHER STATEMENT}

This work is made available according to the conditions of the Creative Commons Attribution-NonCommercialNoDerivatives 4.0 International (CC BY-NC-ND 4.0) licence. Full details of this licence are available at: https://creativecommons.org/licenses/by-nc-nd/4.0/

\section{LICENCE}

CC BY-NC-ND 4.0

\section{REPOSITORY RECORD}

Hobbs, Matthew, Natalie Pearson, Perry J. Foster, and Stuart J.H. Biddle. 2019. "Sedentary Behaviour and Diet Across the Lifespan: An Updated Systematic Review". figshare. https://hdl.handle.net/2134/20308. 


\section{SEDENTARY BEHAVIOUR AND DIET ACROSS THE LIFESPAN: AN UPDATED SYSTEMATIC REVIEW}

*Matthew Hobbs, Carnegie, Leeds Metropolitan University, Leeds, LS6 3QT, UK.

*Natalie Pearson, School of Sport, Exercise and Health Sciences, Loughborough University, Loughborough, LE11 3TU, UK.

Perry, J. Foster, School of Sport, Exercise and Health Sciences, Loughborough University, Loughborough, LE11 3TU, UK.

Stuart J.H. Biddle, School of Sport, Exercise and Health Sciences, Loughborough University, Loughborough, LE11 3TU, UK \& The NIHR Leicester-Loughborough Diet, Lifestyle and Physical Activity Biomedical Research Unit [Now at Institute of Sport, Exercise \& Active Living, Victoria University, Melbourne, Australia].

Corresponding Author:

Matthew Hobbs

227 Fairfax Hall,

Headingley Campus

Leeds Metropolitan University,

Leeds,

LS6 3QT

UK

m.hobbs@leedsmet.ac.uk

+44 (0)113 8124017

\section{Keywords}

Sedentary Behaviour, Diet, Systematic Review, Lifespan.

*First authorship between Matthew Hobbs and Natalie Pearson is considered is joint

Word count $=3592$ 
ABSTRACT

37

Background: Sedentary behaviour and its association with dietary intake in young people and adults are important topics and were systematically reviewed in 2011. There is a need to update this evidence given the changing nature of sedentary behaviour and continued interest in this field. This review aims to assist researchers in better interpreting the diversity of findings concerning sedentary behaviour and weight status.

Objective: To provide an update of the associations between sedentary behaviour and dietary intake across the lifespan.

Methods: Electronic databases searched were Medline, PsychInfo, Cochrane Library, Web of Science and Science Direct for publications between January 2010 and October 2013 thus updating a previous review. Included were observational studies assessing an association between at least one sedentary behaviour and at least one aspect of dietary intake in preschool children (< 5 years), school-aged children (6-11 years), adolescents (12-18 years), and adults (> 18 years).

Results: 27 papers met inclusion criteria (pre-school k=3, school-aged children $k=9$; adolescents $\mathrm{k}=15$; adults $\mathrm{k}=3$ ). For all three groups of young people, trends were evident for higher levels of sedentary behaviour, especially TV viewing, to be associated with a less healthful diet, such as less fruit and vegetable and greater consumption of energy-dense snacks and sugar sweetened beverages. Data for the three studies with adults were less conclusive.

Conclusions: Sedentary behaviour continues to be associated with unhealthy diet in young people in mostly cross-sectional studies. More studies utilising a prospective design are needed to corroborate findings and more studies are needed with adults. 


\section{What are the new findings?}

1. Sedentary time has been implicated in obesity yet this could be due to energy intake rather just low energy expenditure.

2. We provide review-level evidence linking sedentary time and various diet outcomes across the lifespan, including pre-school children for the first time

3. We build on a previous review by providing updated evidence linking sedentary behaviour and elements of an unhealthy diet at a time when sedentary behaviours are continually evolving

\subsection{Introduction}

Sedentary behaviour refers to sitting or lying tasks done in waking hours with low levels of energy expenditure. ${ }^{1}$ Studies show associations between sedentary behaviour (usually assessed as screen-based behaviours such as TV and computer use) and a range of health outcomes, including all-cause mortality, cardiovascular disease, ${ }^{2}{ }^{3}$ poor cardio-metabolic health, ${ }^{4}$ and obesity. ${ }^{5}$

In 2011, Pearson and Biddle ${ }^{6}$ published the first systematic review to investigate associations between sedentary behaviours and dietary intake. This was predicated on the fact that not all associations between sedentary behaviour and health outcomes were consistent and some associations might be due to the influence of third variables, or co-existing health behaviours, such as diet.

In adults, prospective observational cohort studies show evidence of an association between sedentary behaviour and weight status. For example, parent- and self-reported time spent watching television between 5 and 15 years in New Zealand was shown to predict BMI at 26 years of age ${ }^{5}$. The Nurses' Health Study of over 50,000 women $^{7}$ showed that those who were normal weight or overweight at baseline had a $23 \%$ increased risk of developing obesity during 6 years of follow-up for each 2-hour per day increment in time spent watching TV. In another study of over 18,000 women, Blanck et al $^{8}$ showed an elevated risk of weight gain in 
those who were normal weight at baseline and reporting more than 6 hours of leisure time sitting compared to those who reported less than 3 hours/day. For adults, therefore, associations between sedentary behaviour and weight status are suggestive of a positive association. ${ }^{9}$ However, studies either do not control for confounding factors, such as diet or physical activity, or this is done inconsistently across studies. One variable that has been hypothesized to co-vary with some sedentary behaviours, and in particular TV viewing, is diet.

For young people, there has been a longstanding assumption that TV viewing is associated with overweight and obesity. ${ }^{10}$ However, a meta-analysis of mainly cross-sectional studies found that this association was very small. ${ }^{11}$ Also, a review of sedentary behaviour intervention studies showed inconsistent weight loss for young people. ${ }^{12}$ Overall, therefore, sedentary behaviour in the form of screen time is implicated in youth overweight and obesity, but findings are less clear cut than some claim.

For adults and young people, during the time spent watching television, little energy is expended, ${ }^{13}$ and viewers are exposed to numerous advertisements that can influence the type of food desired and consumed. ${ }^{14}{ }^{15}$ Furthermore, eating in front of the TV may differ than when undertaken in other settings. For example, TV or snack commercials may be a distraction resulting in a lack of awareness of food consumption or overlooking food cues. This could disrupt habituation and lead to overconsumption. ${ }^{16}$

Dietary intake and its association with sedentary behaviour in young people and adults is an important topic that may assist researchers in better interpreting the diversity of findings concerning sedentary behaviour and weight status. However, it is recognised that sedentary pursuits using technology can change very quickly. Computer technology has become more mobile and will this change the way people use and interact with such devices. Moreover, TV 
113 channels have increased and the TV viewing experience has changed with greater access to 114 high definition screens and even 3D TV. To this end, it is important to update the review of 115 studies on the association between sedentary behaviour and dietary behaviour. In addition, we 116 feel it is important to differentiate studies with young people into pre-school, children, and 117 adolescents. This systematic review, therefore, provides an update of the associations 118 between sedentary behaviour and diet across the lifespan. 


\subsection{Search Strategy}

121 A literature search was conducted using electronic databases, sedentary behaviour review papers, manual searches of existing reference lists and personal files. The electronic database searches used Medline, PsychInfo, Cochrane Library, Web of Science and Science Direct for publications between January 2010 and October 2013 thus updating the previous review. ${ }^{6}$ To ensure a broad search, a comprehensive list of keywords was used to guide the search process that included the most common forms of sedentary behaviour and dietary intake.

\subsection{Inclusion and Exclusion Criteria}

To be included studies had to: (1) be observational in design; (2) report data on pre-school children ( $<5$ years), school-aged children (6-11 years), adolescents (12-18 years) and adults (>18 years) (or a mean within these ranges) at baseline; (3) measure at least one domain of sedentary behaviour and one aspect of dietary intake; (4) assess an association between at least one sedentary behaviour and one aspect of dietary intake; (5) be published in English between January 2010 to October 2013. Studies that reported physical inactivity (low physical activity) as a measure of sedentary behaviour were excluded. Studies that manipulated a sedentary behaviour and/or aspects of dietary intake were excluded as were studies that did not involve healthy free living individuals were excluded (i.e. chronic illnesses preventing physical activity), although articles that reported risk factors were included.

\subsection{Identification of relevant studies}

142 Titles then abstracts of potentially relevant articles were screened independently by two authors. The full text of any relevant abstracts were then obtained and screened to determine 
whether they met the full inclusion criteria. Any uncertainty was resolved by consulting a third author in order to determine whether to include the paper in the final sample upon reading the full text. Studies that did not meet the inclusion criteria at this stage were excluded.

\subsection{Data Extraction}

Two authors extracted the data from relevant articles in accordance with a standardised form developed for a previous review. ${ }^{6}$ The following data were extracted from each paper: (1) author and year; (2) study design and duration of follow-up if prospective; (3) geographical location; (4) age group; (5) sample size and sub-groups; (6) sedentary behaviour outcome and primary measure; (7) dietary intake outcome and primary measure; (8) timing, reliability and validity of assessment methods; (8) the analysis and results of an association between sedentary behaviour and dietary intake. Authors were contacted when missing information prevented data extraction. All data extraction was completed by the researchers independently. Any differences or discrepancies (interpretation errors or factual errors, such as transposed information) were discussed and resolved. Finally, inter-rater reliability was calculated and reported for study quality and data extraction.

TABLE 1 \& 2 (SUPPLEMENTARY DATA)

\subsection{Study Quality}

The quality of the studies included in this review was assessed with a previously used scale. ${ }^{6}$ Studies were given a score based on sampling procedure, sample size, response rates, the validity and reliability of the measures used to assess sedentary behaviour and dietary intake and whether confounders had been considered in the analysis. Each included paper was given a score out of 16 with a higher score meaning higher study quality. Studies were categorised 

as high (scoring 12+), moderate (scoring 6-11), and poor (scoring 0-5) quality. There was good initial agreement for study quality $(91 \% \mathrm{r}=0.98)$ between authors.

171 


\subsection{Results}

\section{$173 \quad 3.1$ Flow of studies included}

174 The literature search identified 13,883 articles from which 209 were identified as potentially relevant upon reviewing the title. Following the screening of the full text of the article 27 were identified that sufficiently examined the association between sedentary behaviour and dietary intake. Figure 1 presents the flow of papers from citations retrieved. The results are reported separately for pre-school children, school-aged children, adolescents and adults.

INSERT FIGURE 1 AROUND HERE

\subsection{Study Quality}

Study quality for studies including children of pre-school age ranged from 2/16 to 6/16, median $=6$ [individual scores $6: n=2^{17} 18 ; 2: n=1^{19}$ ]. Study quality in studies including children ranged from $4 / 16$ to $8 / 16$, median $=6$ [individual scores $6: n=4^{17182021} ; 7: n=2^{22} 23$; 8: $\left.n=1^{24} ; 4: n=1^{25} ; 5: n=1^{26}\right]$.

Adolescent study quality ranged from $4 / 16$ to $15 / 16$, median $=8$ [scores $19: n=1^{27} ; 10$ : $n=4^{28-}$

31: 8: $n=2^{32} 33 ; 7: n=1^{34} ; 6: n=5^{1835-38} ; 5: n=1^{39} ; 4: n=1^{40}$. Study quality scores in adults for studies ranged from $5 / 16$ to $7 / 16$, median $=6$ [scores $7: n=1^{41} ; 6: n=1^{18} ; 5: n=1 .^{42}$

\subsection{Associations between Sedentary Behaviour and Diet in Pre-school Children}

193 Three studies (three samples) including pre-school children were eligible for review (Table 3). Two studies were conducted in Australia and one in the USA. Two studies examined associations between sedentary behaviour and dietary outcomes for boys and girls combined, one study examined associations separately for boys and girls. The majority used a cross- 
sectional research design $(\mathrm{n}=2)$, two of the studies assessed sedentary behaviour through parental report and one through interview. Dietary behaviour was also assessed through parental report $(\mathrm{n}=2)$ and interview $(\mathrm{n}=1)$. In this one instance, the dietary behaviour (based on the Healthy Eating Index (HEI) 2005) was collected from two, averaged interviewadministered 24 hour dietary recalls. The sedentary behaviour information was also collected as part of this interview. TV viewing was the most commonly assessed sedentary behaviour in association with dietary intake, studied in all three studies. In studies including children of pre-school age, five dietary behaviours were identified.

\section{INSERT TABLE 3 HERE}

Average weekday and weekend TV viewing, weekday and weekend non-commercial and weekday commercial TV viewing were inversely associated with fruit and vegetable consumption in one sample. However, weekday commercial TV viewing was positively associated with fruit and vegetable consumption in one sample. Finally, TV viewing was inversely associated with the healthy eating index in both boys and girls in one sample and with vegetable intake in one other sample.

TV viewing was positively associated with energy-dense food in two of two samples and positively associated with fast food in one sample. There was one longitudinal study ${ }^{17}$ which scored well on study quality and had a large sample size ( $\mathrm{n}=4983)$. This study corroborates the results from the limited cross sectional studies showing that TV viewing is positively associated with energy-dense food. Overall, sedentary behaviour in pre-school children seems to be trending towards an association with elements of an unhealthy diet, yet caution is required when interpreting results due to the paucity of studies. That said, these results are confirmed in a large high quality longitudinal study. 


\subsection{Associations between Sedentary Behaviour and Diet in Children}

224

225

Nine studies (nine samples) of school-age children were eligible for review (Table 4). Three studies were conducted in Australia and two in Norway. The remaining four were carried out in Canada, Netherlands, USA and Belgium. Eight studies examined associations between sedentary behaviour and dietary outcomes for boys and girls combined whilst one study examined associations separately for boys and girls. The majority of studies used a crosssectional design ( $n=6$ ), six assessed sedentary behaviour through self-report and three by parental report. One used an objective measure of accelerometry yet specific methodological information on cut-points was withheld. Dietary behaviour was assessed through 24 hour recall $(n=3)$, food diary $(n=4)$ and questionnaire $(n=3)$. TV viewing was the most commonly assessed sedentary behaviour in association with dietary intake $(n=6)$. Nine dietary behaviours were identified and tabulated, the most common being energy-dense food.

\section{INSERT TABLE 4 AROUND HERE}

Sedentary behaviour was inversely associated with vegetable intake in two samples (one assessed TV viewing and the other both computer use and screen time), yet computer use was positively associated with vegetable intake in one sample. Sedentary behaviour was inversely associated with fruit intake in two samples (one assessed TV viewing and the other both computer use and screen time), yet computer use had no association with fruit intake in one sample. Finally, homework was positively associated with the healthy eating index (one sample) and TV viewing in boys and girls and computer use was inversely associated with the healthy eating index (two samples). 
Sedentary behaviour was positively associated with energy-dense food in five samples (four

247

248

249

250

251

252

253

254

255

256

257

258

259

260

261

262

263

264

265

266

267

268

269 assessed TV viewing and the other both screen time and computer use). However, computer use was inversely associated with energy-dense food in one sample. Sedentary behaviour was positively associated with fat, sugar and total calorie intake in three samples (three used selfreport and one study objectively assessed sedentary behaviour) and was positively associated with sugar sweetened beverage intake in two samples (one assessed screen time and computer use and the other assessed computer use and TV viewing). Finally, TV viewing was positively associated with diet quality based on fat and sugar intake (one sample).

Two longitudinal studies assessed the association between sedentary behaviour and diet in children. ${ }^{1724}$ Both scored at and above the median score on study quality and had moderate to large sample sizes ( $n=908$ and $n=4464)$. These studies corroborated findings from the crosssectional evidence that various sedentary behaviours (TV viewing, screen time and computer use) are positively associated with consumption of energy-dense food and sugar sweetened beverages. Overall, sedentary behaviour in children again seems to be trending towards an association with elements of a less healthy diet. However, the number of comparisons is small, the studies are often diverse in the measurement methods adopted, and are often crosssectional in design in both pre-school and children. This makes it difficult to draw meaningful conclusions. That said, two medium to large longitudinal studies of moderate to good quality did show associations between sedentary behaviour and unhealthy diet.

\subsection{Associations between Sedentary Behaviour and Diet in Adolescents}

All fifteen studies were cross-sectional in design. Data were reported separately for gender in eight studies. The remaining seven studies combined male and female data. Participants were 
aged between 11 and 19 years. Three studies reported data from the US and two presented combined data from Europe.

The majority of studies (60\%) measured TV-viewing as the sedentary behaviour. Two of these also separately measured computer use and one also measured study time. A further two studies measured internet and video game use alongside TV-viewing, two additional studies measured computer use, internet for study, video games and study time alongside TVviewing. One study measured screen time as one outcome $(\mathrm{TV}+$ video games + computer use + internet use), another also measured small screen recreation time (TV+/or video+/or DVDs + video games + computer games + computer not for homework) and sedentary education time (reading + homework). Sedentary behaviour was assessed by self-report in the majority of studies, one study used an interview administered technique. Sedentary behaviour was measured using questionnaires in all fifteen adolescent studies (Table 5).

\section{INSERT TABLE 5 HERE}

A total of eighteen dietary behaviours were assessed. Eleven studies assessed diet by selfreport and the remaining study used a telephone interview technique. Diet was measured using unnamed questionnaires in eight studies, a web-based food behaviour questionnaire in another study, food frequency questionnaire in two studies, and using 24-hour recall methods in three studies. Finally, one study used a combination of a food frequency questionnaire and 24-hour recall.

Separate measures of TV-viewing and various categories of screen time were positively associated with sugar sweetened beverages in five of five samples and inversely associated in 
one sample. Separate measures of TV-viewing and various categories of screen time were also inversely associated with separate measures of fruit and vegetable consumption in three of three studies, and positively associated in another. Further, the inclusion of sedentary behaviours such as 'internet use for study' and ‘studying' evident in one study resulted in a positive association with a separate measure of fruit and vegetable consumption. TV-viewing and computer use were also inversely associated with a composite measure of fruit and vegetable consumption in one of one sample.

302 analyses with fewer than five studies, as estimates of an association may be imprecise. 
Based on the lack of evidence, it is difficult to provide a clear conclusion on the association between TV-viewing and dietary behaviour in adults. Although limited, the available evidence tends to suggest that high TV-viewing is positively associated with total energy intake and unhealthy diet quality. Similar to findings with adolescents, caution should be taken when interpreting associations regarding adults due the lack of research.

\section{INSERT TABLE 6 HERE}

\subsection{Discussion}

This systematic review builds on the published review by Pearson and Biddle. ${ }^{6}$ An update was attempted because technology-based sedentary behaviours are likely to be changing quickly, and it is timely to examine new papers that were emerging but by differentiating preschool children from children and adolescents. Adults were again included to allow for a lifespan approach. However, studies are failing to provide contextual information about how TV is viewed, thus we were unable to further differentiate results on this basis. For example, we have shown that children multi-task while 'watching' TV. ${ }^{43}$ Future research on diet and screen viewing needs to differentiate types of screen viewing as this will inevitably change with time.

For pre-school children, three new studies were found since early 2010. These showed a clear trend for greater time in sedentary behaviour (mainly TV viewing) to be associated with unhealthy eating. This showed in less fruit and vegetable consumption and lower scores on a healthy eating index, as well as higher levels of energy dense food and fast food. In the 2011 review, we combined this age group with older children. The present review, therefore, shows that the coupling of screen time and possibly commercial TV viewing time with an unhealthy diet starts at an early age and leads to the obvious conclusion that parental, family 
and other interventions are required with children in the first few years of life. However, caution is required at this stage due to the small number of studies and the difficulty of eliciting such information from young children or their carers. Clearly this is an important area of research development.

For children aged 5-11 years, results across nine studies showed a clear trend for sedentary behaviour to be associated with a less healthy diet. With 19 studies reported by Pearson and Biddle for pre-adolescent children, including pre-school children, this shows a continued interest in diet and sedentary behaviour in this age group. In the current review, sedentary screen time, and mainly TV viewing, is associated with greater consumption of energy-dense food, fat, sugar, sugar sweetened beverages and total caloric intake. It is also associated with consumption of less fruit and vegetables.

Confidence in these trends in enhanced by two reasonably large longitudinal studies that show that screen time is associated energy-dense food and sugar sweetened beverage consumption. Sugar sweetened beverages have been implicated in weight gain ${ }^{44} 45$ and might be one mechanism linking screen time with obesity and account for the variable findings in this area. In other words, weight status may be as much to do with energy consumption as it is with low energy expenditure from sedentary time, thus accounting for inconsistency of findings when just investigating TV and weight status. ${ }^{10}$ Studies are required that investigate further this association, including availability of food and drinks during different sedentary behaviours, and prompts or cues that encourage or discourage such consumption.

With 15 studies reported in the current review concerning associations between sedentary behaviour and diet in adolescents, this shows that researchers continue to view this topic and age group as important. In less than four years, this represents more than a $50 \%$ increase in 
the number of studies. However, while there is a trend for higher levels of sedentary behaviour to be associated with poorer diet, there are rather few studies assessing the same sedentary behaviour and same diet outcome variable. Future studies need to build on these associations by ensuring that similar measures are taken. It appears that TV and, to a certain extent computer screen time, are implicated in being associated with poorer diet. The dietary outcomes, therefore, need standardising by studies ensuring that they measure at least fruit and vegetable intake, energy-dense snacks, and sugar sweetened beverages. That way a more comprehensive picture will emerge for adolescents at an important time of change in this age group.

Data on adults have not expanded much since the last review. Only three studies were reviewed in the present paper, with 11 in 2011. With so few studies, firm conclusions are not possible, although similar trends noted elsewhere in this review are still evident. Future studies need more data on the context of sedentary behaviours and what might be cuing certain dietary behaviours in the presence of screen or other sitting behaviours.

\section{Conclusion}

In conclusion, sedentary behaviour, mainly in form of screen viewing and especially TV, is associated with indicators of unhealthy dietary intake in pre-school children, school-aged children and adolescents in predominantly cross-sectional studies. The results for adults are sparse and less clear. Findings largely confirm and extend the review published in 2011. We have added to knowledge by investigating pre-school children separately, and documenting the continued study of sedentary behaviour and diet in young people. Research on adults needs to develop. Future studies need to be longitudinal in design, use standard measures of diet, include a wider variety of sedentary behaviours, as well as document the context that sedentary behaviour may be associated with dietary intake. 
393

394

395

396

397

398 


\section{References}

400

401

402

403

404

405

406

407

408

409

410

411

412

413

414

415

416

417

418

419

420

421

422

423

424

425

426

427

428

429

430

431

432

433

434

435

436

437

438

439

440

441

442

443

444

445

446

447

448

449

1. Sedentary Behaviour Research Network. Letter to the Editor: Standardized use of the terms "sedentary" and "sedentary behaviours". Applied Physiology, Nutrition \& Metabolism 2012;37:540-42.

2. Katzmarzyk PT, Church TS, Craig CL, Bouchard C. Sitting time and mortality from all causes, cardiovascular disease, and cancer. Medicine and Science in Sports \& Exercise 2009;41(5):998-1005.

3. Dunstan DW, Barr ELM, Healy GN, Salmon J, Shaw JE, Balkau B, et al. Television viewing time and mortality: The Australian Diabetes, Obesity and Lifestyle Study (AusDiab). Circulation 2010;121:384-91.

4. Dunstan DW, Salmon J, Healy GN, Shaw JE, Jolley D, Zimmet PZ, et al. Association of television viewing with fasting and 2-hr post-challenge plasma glucose levels in adults without diagnosed diabetes. Diabetes Care 2007;30:516-22.

5. Hancox RJ, Milne BJ, Poulton R. Association between child and adolescent television viewing and adult health: A longitudinal birth cohort study. The Lancet 2004;364:257-62.

6. Pearson N, Biddle S. Sedentary Behavior and Dietary Intake in Children, Adolescents and Adults. American Journal of Preventative Medicine 2011;41(2):178-88.

7. Hu FB, Li TY, Colditz GA, Willett WC, Manson JE. Television watching and other sedentary behaviors in relation to risk of obesity and type 2 diabetes mellitus in women. Journal of the American Medical Association 2003;289(14):1785-91.

8. Blanck HM, McCullough ML, Patel AV, Gillespie C, Calle EE, Cokkinides VE, et al. Sedentary behavior, recreational physical activity, and 7-year weight gain among postmenopausal U.S. women. Obesity 2007;15:1578-88.

9. Williams DM, Raynor HA, Ciccolo JT. A review of TV viewing and its association with health outcomes in adults. American Journal of Lifestyle Medicine 2008;2:250-59.

10. Dietz WH, Gortmaker SL. Do we fatten our children at the television set? Obesity and television viewing in children and adolescents. Pediatrics 1985;75:807-12.

11. Marshall SJ, Biddle SJH, Gorely T, Cameron N, Murdey I. Relationships between media use, body fatness and physical activity in children and youth: A meta-analysis. International Journal of Obesity 2004;28:1238-46.

12. DeMattia L, Lemont L, Meurer L. Do interventions to limit sedentary behaviours change behaviour and reduce childhood obesity? A critical review of the literature. Obesity Reviews 2007;8:69-81.

13. Klesges RC, Shelton ML, Klesges LM. Effects of television on metablic rate: potential implications for childhood obesity. Pediatrics 1993;91:281-86.

14. Dennison BA, Edmunds LS. The role of television in childhood obesity. Progress in Pediatric Cardiology 2008;25:191-97.

15. Scully M, Dixon H, Wakefield M. Association between commercial television exposure and fastfood consumption among adults. Public Health Nutrition 2009;12(01):105-10.

16. Temple JL, Giacomelli AM, Kent KM, Roemmich JN, Epstein LH. Television watching increases motivated responding for food and energy intake in children. Am J Clin Nutr 2007;85(2):35561.

17. Brown J, Broom D, Nicholson J, Bittman M. Do working mothers raise couch potato kids? Maternal employment and children's lifestyle behaviours and weight in early childhood. Social science \& medicine 2010;10:1816-24.

18. Sisson S, Shay C, Broyles S, Leyva M. Television-viewing time and dietary quality among U.S. children and adults. American Journal of Preventative Medicine 2012;43(2):196-200.

19. Cox R, Skouteris H, Rutherford L, Fuller-Tyszkiewicz M, Dell' Aquila D, Hardy L. Television viewing, television content, food intake, physical activity and body mass index: a cross-sectional study of preschool children aged 2-6 years. Health Promotion Journal of Australia 2012;23(1):5862. 
20. Danielsen $Y$, Júlíusson $P$, Nordhus I, Kleiven $M$, Meltzer $H$, Olsson $S$, et al. The relationship between life-style and cardio-metabolic risk indicators in children: the importance of screen time. Acta paediatrica 2011;100(2):253-59.

21. Brown J, Nicholson J, Broom D, Bittman M. Television Viewing by School-Age Children: Associations with Physical Activity, Snack Food Consumption and Unhealthy Weight. Social Indicators Research 2011;101:221-25.

22. Ouwens $M$, Cebolla A, Van Strien T. Eating style, television viewing and snacking in preadolescent children. Nutricion Hospitalaria 2012;27(4):1072-78.

23. Seghers J, Rutter C. Clustering of multiple lifestyle behaviours and its relationship with weight status and cardiorespiratory fitness in a sample of Flemish 11- to 12-year-olds. Public health nutrition 2010;13(11):1838-46.

24. Gebremariam M, Bergh I, Andersen L, Ommundsen Y, Totland T, Bjelland M, et al. Are screenbased sedentary behaviors longitudinally associated with dietary behaviors and leisure-time physical activity in the transition into adolescence? Int. J. Behav. Nutr. Phys. Act. 2013;10:18.

25. Fuller-Tyszkiewicz M, Skouteris $H$, Hardy L, Halse $C$. The associations between TV viewing, food intake, and BMI. A prospective analysis of data from the Longitudinal Study of Australian Children. Appetite 2012;59:945-48.

26. McCormack G, Hawe P, Perry R, Blackstaffe A. Associations between familial affluence and obesity risk behaviours among children. Pediatric Child Health 2011;16(1):19-25.

27. Ranjit N, Evans M, Byrd-Williams C, Evans A, Hoelscher D. Dietary and activity correlates of sugarsweetened beverage consumption among adolescents. Pediatrics 2010;126(4):754-61.

28. Arora M, Nazar G, Gupta V, Perry C, Srinath R, Stigler M. Association of breakfast intake with obesity, dietary and physical activity behaviour among urban school-aged adolescents in Dehli, India: Results of a cross-sectional study. BMC Public Health 2012;12:881-93.

29. Santaliestra-Pasias A, Mouratidou T, Verbestel V, Huybrechts I, Gottrand F, Le Donne C, et al. Food consumption and screen-based sedentary behaviours in European adolescents. Archives of Paediatrics and Adolescent Medicine 2012;166(11):1010-20.

30. Verzeletti C, Maes L, Santinell M, Baldassari D, Vereecken C. Food-related family lifestyle associated with fruit and vegetable consumption among young adolescents in Belgium Flanders and the Veneto Region of Italy. Appetite 2010;54:394-97.

31. Williams S, Mummery K. Associations between adolescent nutrition behaviours and adolescent and parent characteristics. . Nutrition and Pediatrics 2012;69:95-101.

32. Al-Hazzaa H, Al-Sobayel H, Abahussain N, Qahwaji D, Alahmadi M, Musaiger A. Association of dietary habits withe levels of physical activity and screen time among adolescent living in Saudi Arabia. J. Hum. Nutr. Diet. 2013;27:1-10.

33. Fernandes R, Christofaro D, Casonatto J, Kuwaguti S, Ronque E, Cardoso J, et al. Cross-sectional association between healthy and unhealthy food habts and leisure physical activity in adolescents. Journal de Pediatria 2011;87(3):252-56.

34. Ciccone J, Woodruff S, Fryer K, Campbell T, Cole M. Associations among evening snacking, screen time, weight status, and overall diet quality in young adolescents. Applied Physiology Nutrition and Metabolism 2013;38:789-94.

35. Cuenca-Garci'a M, Ruiz J, Ortega F, Labayen I, Gonzalez-Gross M, Moreno L, et al. Association breakfast consumption with objectively measured and self-reported physical activity, sedentary time and physical fitness in European adolescents: the HELENA (Healthy Lifestyle in Europe by Nutrition in Adolescence) study. Public health nutrition 2013;11:1-11.

36. Del Mar Bibiloni M, Martinez E, Llull R, Pons A, Tur J. Western and Mediterranean dietary patterns among Balearic Islands' adolescents: Socio-economic and lifestyle determinants. Public health nutrition 2011;15(4):683-92. 
522

37. Honkala S, Behbehani J, Honkala E. Daily consumption of sugary drinks and foods as a behavioural risk for health of adolescents in Kuwait. Oral Health and Preventitive Densitry 2012;10:113-22.

38. Shi L, Mao Y. Excessive recreational computer use and food consumption behaviour among adolescents. Ital. J. Pediatr. 2010;36:52-55.

39. Lee J, Jun N, Baik I. Associations between dietary patterns and screen time among Korean adolescents. Nutrition Research and Practice 2013;7(4):330-35.

40. Al-Hazzaa H, Abahussain N, Al-Sobayel H, Qahwaji D, Mulsager A. Physical activity, sedentary behaviours and dietary habits among Saudi adolescents relative to age, gender and religion. Int. J. Behav. Nutr. Phys. Act. 2011;8:140-54.

41. Huffman F, Vaccaro J, Exebio J, Zarini G, Katz T, Dixon Z. Television watching, diet quality, and physical activity and diabetes among three ethnicities in the United States. Journal of Environmental and Public Health 2012;20:1-10.

42. Tucker L, Tucker J. Television viewing and obesity in 300 women: Evaluation of the pathways of energy intake and physical activity. Obesity 2011;19(10):950-56.

43. Jago R, Sebire SJ, Gorely T, Hoyos Cillero I, Biddle SJH. "I'm on it 24/7 at the moment": A qualitative examination of multi-screen viewing behaviours among UK 10-11 year olds. Int. J. Behav. Nutr. Phys. Act. 2011;8(1):85.

44. Malik VS, Schulze MB, Hu FB. Intake of sugar-sweetened beverages and weight gain: a systematic review. American Journal of Clinical Nutrition 2006;84(2):274-88.

45. Hu FB. Resolved: there is sufficient scientific evidence that decreasing sugar-sweetened beverage consumption will reduce the prevalence of obesity and obesity-related diseases. Obesity Reviews 2013;14(8):606-19.

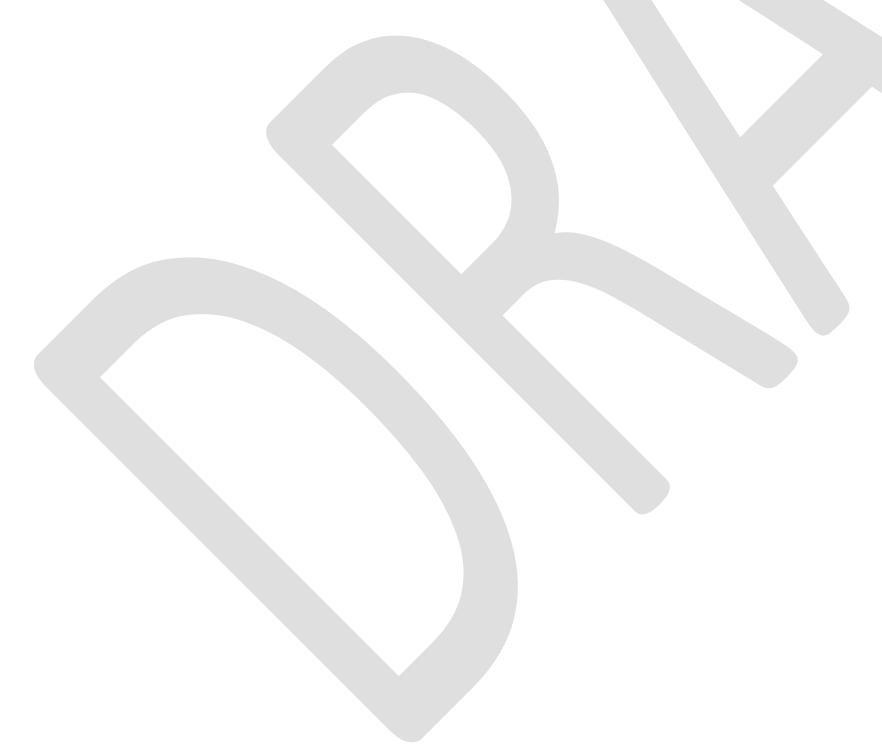


Table 1. Characteristics of early years and child studies included in the review: sample size, gender, study design, nature of sedentary behaviour assessed, assessment and measurement of sedentary behaviour, type of dietary behaviours assessed, assessment and measurement of dietary behaviour and country of study.

\begin{tabular}{|c|c|c|c|c|}
\hline & \multicolumn{2}{|c|}{$\begin{array}{c}\text { Early years } \\
(>2 x<5 \text { years })\end{array}$} & \multicolumn{2}{|c|}{$\begin{array}{c}\text { Children } \\
(\geq 5 \times<11) \\
\end{array}$} \\
\hline & References & No. of samples & References & No. of samples \\
\hline Sample size & & 3 & & 9 \\
\hline$<100$ & - & - & 4 & 1 \\
\hline 100-199 & 3 & 1 & - & - \\
\hline 200-299 & - & - & 7 & 1 \\
\hline $300-499$ & - & - & 10 & 1 \\
\hline $500-999$ & - & - & 6,8 & 2 \\
\hline $1000-2999$ & $1^{\mathrm{n}}, 9^{\mathrm{c}}$ & 2 & $1^{o}, 9^{\mathrm{d}}$ & 2 \\
\hline $3000-4999$ & - & - & 2,5 & 2 \\
\hline \multicolumn{5}{|l|}{ Gender } \\
\hline Boys and girls combined & $1^{\mathrm{n}}, 3$ & 2 & $\begin{array}{l}1^{0}, 2,4,5,6,7 \\
8,10\end{array}$ & 8 \\
\hline Boys and girls separately & $9^{c}$ & 1 & $9^{\mathrm{d}}$ & 1 \\
\hline \multicolumn{5}{|l|}{ Study design } \\
\hline Cross sectional & $3,9^{c}$ & 2 & $2,4,7,8,9^{\mathrm{d}}, 10$ & 6 \\
\hline Longitudinal & $1^{\mathrm{n}}$ & 1 & $1^{0}, 5,6$ & 3 \\
\hline \multicolumn{5}{|l|}{ Study quality } \\
\hline Poor & 3 & 1 & 5,7 & 2 \\
\hline Moderate & $1^{\mathrm{n}}, 9^{\mathrm{c}}$ & 2 & $\begin{array}{l}1^{0}, 2,4,6,8, \\
9^{d}, 10\end{array}$ & 7 \\
\hline High & - & - & $-\quad 2$ & - \\
\hline \multicolumn{5}{|l|}{$\begin{array}{l}\text { Sedentary behaviour } \\
\text { assessed }\end{array}$} \\
\hline TV viewing & $1^{\mathrm{n}}, 3,9^{\mathrm{c}}$ & 3 & $1^{0}, 2,5,7,8,9^{\mathrm{d}}$ & 6 \\
\hline $\begin{array}{l}\text { TV viewing non-commercial } \\
\text { weekday }\end{array}$ & 3 & 1 & - & - \\
\hline $\begin{array}{l}\text { TV viewing commercial } \\
\text { weekday }\end{array}$ & 3 & 1 & - & - \\
\hline $\begin{array}{l}\text { TV viewing non-commercial } \\
\text { weekend }\end{array}$ & 3 & 1 & - & - \\
\hline $\begin{array}{l}\text { TV viewing non-commercial } \\
\text { weekend }\end{array}$ & 3 & 1 & - & - \\
\hline Sedentary activity & - & - & $4^{\mathrm{a},} 4^{\mathrm{b}}$ & 1 \\
\hline Computer (games or use) & - & - & $6^{\mathrm{i}}, 7$ & 2 \\
\hline Screen time & - & - & $6^{\mathrm{n}}, 10$ & 2 \\
\hline Homework & - & - & 10 & 1 \\
\hline \multicolumn{5}{|l|}{$\begin{array}{c}\text { Assessment of sedentary } \\
\text { behaviour }\end{array}$} \\
\hline Parent reported & $1^{\mathrm{n}}, 3$ & 2 & $1^{0}, 2,5$ & 3 \\
\hline Accelerometer & - & - & $4^{\mathrm{a}}$ & 1 \\
\hline Self-report & $9^{\mathrm{C}}$ & 1 & $\begin{array}{l}4^{b}, 67,8,9^{d}, \\
10\end{array}$ & 6 \\
\hline \multicolumn{5}{|l|}{$\begin{array}{l}\text { Measure of sedentary } \\
\text { behaviour }\end{array}$} \\
\hline 24 hour recall & $1^{\mathrm{n}}$ & 1 & $1^{0}, 2$ & 2 \\
\hline Questionnaire & $3,9^{c}$ & 1 & $\begin{array}{l}4^{\mathrm{b}}, 5,6,7,8, \\
9^{\mathrm{d}}, 10\end{array}$ & 7 \\
\hline Accelerometer & - & - & $4^{\mathrm{a}}$ & 1 \\
\hline Dietary behaviour assessed & & & & \\
\hline
\end{tabular}




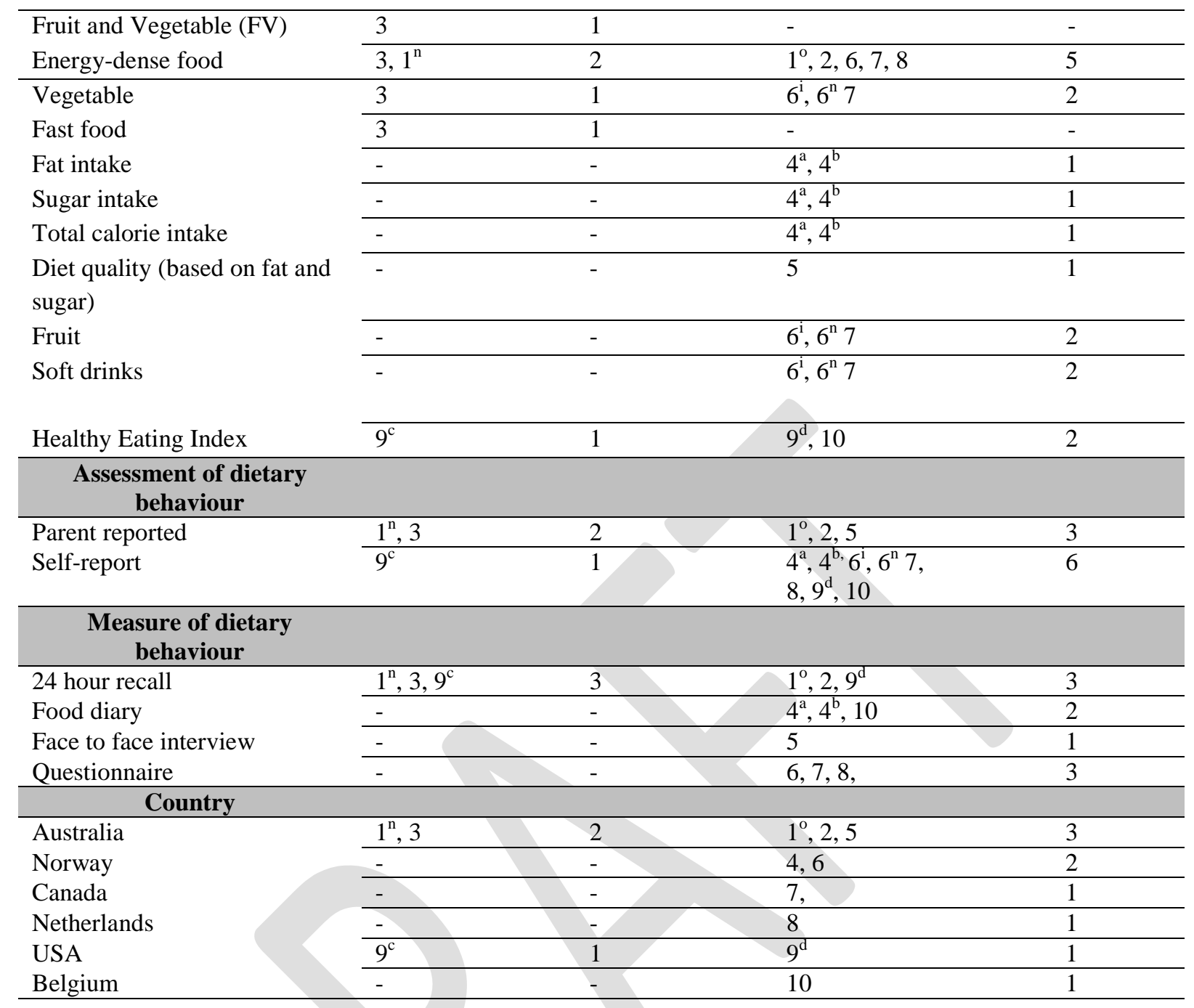

For reference 4: abjectively assessed sedentary activity using accelerometer, ${ }^{\mathrm{b}}$ Assessed using screen time questionnaire; for reference 9: ${ }^{\mathrm{c}}$ early years aged $2-5$, ${ }^{\mathrm{d}}$ children aged 6-11 years of age; for reference 1 : ${ }^{\mathrm{n}}$ early years aged $4-5,{ }^{\circ}$ children aged 6-7.

Note:

enon-commercial TV weekday, ${ }^{\mathrm{f}}$ non-commercial TV weekend day, ${ }^{\mathrm{g}}$ commercial TV weekday, ${ }^{\mathrm{h}}$ commercial TV weekend day,

${ }^{\mathrm{i}} \mathrm{TV}$ weekday, ${ }^{\mathrm{j}} \mathrm{TV}$ weekend.

${ }^{\mathrm{B}}$, boys only; ${ }^{\mathrm{G}}$, girls only

${ }^{\prime}$ computer use (games or general use), ${ }^{\mathrm{m}}$ homework, ${ }^{\mathrm{n}}$ screen time

Reference numbers: (1) Brown et al. (2010); (2) Brown et al. (2011); (3) Cox et al. (2012); (4) Danielson et al. (2011); (5) Fuller et al. (2012); (6) Gebremariam et al. (2013); (7) McCormack et al. (2011); (8) Ouwens et al. (2012); (9) Sisson et al. (2012); (10) Seghers and Rutten (2010). 
Table 2. Characteristics of adolescent and adults studies included in systematic review: sample size, gender, study design, nature of sedentary behaviour assessed, assessment and measurement of sedentary behaviour, type of dietary behaviours assessed, assessment and measurement of dietary behaviour, and country of study.

\begin{tabular}{|c|c|c|c|c|}
\hline & \multicolumn{2}{|c|}{ Adolescents (12-18 years) } & \multicolumn{2}{|c|}{ Adults (18+ years) } \\
\hline & References & $\begin{array}{l}\text { No. of } \\
\text { samples }\end{array}$ & References & $\begin{array}{c}\text { No. of } \\
\text { samples }\end{array}$ \\
\hline \multicolumn{5}{|l|}{ Sample size } \\
\hline $300-499$ & 16 & 1 & 17 & 1 \\
\hline $500-999$ & 8 & 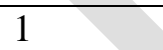 & 10 & 1 \\
\hline 1000-2999 & $9,6,7,3,1,2,4,5$ & 9 & - & - \\
\hline $3000-4999$ & 14,13 & 2 & - & - \\
\hline$>5000$ & 15,11 & 2 & 14 & 1 \\
\hline \multicolumn{5}{|l|}{ Gender } \\
\hline Female only & + & - & 17 & 1 \\
\hline Male and female combined & $9,7,13,15,2,4$ & 6 & - & - \\
\hline Male and female separately & $14,6,12,3,16,1,11,5,8$ & 9 & 14,10 & 2 \\
\hline \multicolumn{5}{|l|}{ Study design } \\
\hline Cross sectional & $\begin{array}{l}14,9,6,7,12,3,16,13,15,1 \text {, } \\
2,4,5,8\end{array}$ & $15 \bigcirc$ & $14,10,17$ & 3 \\
\hline \multicolumn{5}{|l|}{ Sedentary behaviour assessed } \\
\hline TV viewing & $14,9,6,7,12,3,13,15,11,8$ & 10 & $14,10,17$ & 3 \\
\hline $\begin{array}{l}\text { Screen time (TV + video games + computer use + } \\
\text { internet use) }\end{array}$ & $1,2,4,5$ & 4 & - & - \\
\hline Computer use & $12,3,13,11,8$ & 5 & - & - \\
\hline Video use & 11 & 1 & - & - \\
\hline Internet use & +2 & 1 & - & - \\
\hline Internet for study & 12,5 & 2 & - & - \\
\hline Video games & 12,8 & 2 & - & - \\
\hline Studying & 12,3 & 2 & - & - \\
\hline $\begin{array}{l}\text { Small screen recreation time (TV +/or video +/or } \\
\text { DVDs + video games + computer games +computer } \\
\text { not for homework) }\end{array}$ & 16 & 1 & - & - \\
\hline Sedentary education time (reading + homework) & 16 & 1 & - & - \\
\hline Assessment of sedentary behaviour & & & & \\
\hline
\end{tabular}




\begin{tabular}{|c|c|c|c|c|}
\hline $\begin{array}{l}\text { Self-report } \\
\text { Interviewer administered }\end{array}$ & $\begin{array}{l}14,9,6,7,12,3,16,15,1,11,2, \\
4,5,8, \\
13\end{array}$ & 13 & $14,10,17$ & 3 \\
\hline \multicolumn{5}{|l|}{ Measure of sedentary behaviour } \\
\hline Questionnaire & $\begin{array}{l}14,9,6,7,12,1,2,3,16,13,15 \\
11,4,5,8\end{array}$ & 15 & $14,10,17$ & 3 \\
\hline \multicolumn{5}{|l|}{ Dietary behaviour assessed } \\
\hline Fruit & $7,12,15,1,2,4$ & 6 & & - \\
\hline Vegetables & $7,12,15,1,2,4$ & 6 & & - \\
\hline Juices & 12 & 1 & sen & - \\
\hline Savoury snacks & 12 & 1 & - & - \\
\hline Fast food & $7,13,1$ & 3 & - & - \\
\hline Fried foods & 1 & 1 & 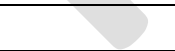 & - \\
\hline High-sugar foods & 13,2 & 2 & & - \\
\hline Total energy intake & - & - & 17 & 1 \\
\hline Western dietary pattern & 6,8 & 2 & & - \\
\hline Frequency of breakfast consumption & $1,2,5$ & 3 & & - \\
\hline Snacks & 7,4 & 2 & & - \\
\hline Healthy food index score & 14,16 & 2 & 14 & 1 \\
\hline Food-frequency questionnaire & - & - & 10 & 1 \\
\hline Mediterranean dietary pattern & 6,8 & 2 & & - \\
\hline Korean dietary pattern & & 1 & & \\
\hline Milk/dairy & $12,1,2,4$ & 4 & & - \\
\hline Cakes & $9,12,1,2$ & 4 & & - \\
\hline Energy drinks & $1,11,2$ & 3 & & - \\
\hline Sweets & $9,1,2,4$ & 4 & & - \\
\hline Sugar sweetened beverages & $12,13,1,11,2$ & 5 & & - \\
\hline Soda & 11 & 1 & & - \\
\hline \multicolumn{5}{|l|}{ Assessment of dietary behaviour } \\
\hline Self-report & $14,9,6,7,12,3,15,11,2,4,5,8$ & 13 & $14,10,17$ & 3 \\
\hline Telephone interview & 13 & 1 & - & - \\
\hline \multicolumn{5}{|l|}{ Measure of dietary behaviour } \\
\hline Food Frequency Questionnaire (FFQ) & $6,11,8$ & 3 & 10 & 1 \\
\hline
\end{tabular}


Other questionnaire

24-hour recall

\begin{tabular}{llll}
\hline $9,7,3,13,15,1,2,4$ & 9 & & - \\
\hline $14,6,12,5$ & 4 & 14 & 1 \\
\hline- & - & 17 & 1 \\
\hline
\end{tabular}

Weighed food records

\begin{tabular}{llll}
$14,13,11$, & 1 & 14,10 & 2 \\
\hline 4 & 1 & - & - \\
\hline 16 & 1 & - & - \\
\hline 15 & 1 & - & - \\
\hline 15 & 1 & - & - \\
\hline 7 & 1 & - & - \\
\hline 6 & 1 & - & - \\
\hline 3 & 1 & - & - \\
\hline 1,2 & 2 & - & - \\
\hline 9 & 1 & - & - \\
\hline 8 & 1 & - & - \\
\hline 12,5 & 2 & - & - \\
\hline- & - & 17 & 1
\end{tabular}

Country/Region

United States (US)

Canada

Australia

Italy

Belgium - Flanders

Brazil

Balearic Islands

India

Saudi Arabia

Kuwait

Korea

Europe

Not stated

Note: For reference 7: 1=children and adolescents included in analysis (mean age M 13.8 years, F 13.9 years). For reference 15: study from the larger Health Behaviour in

School-aged Children (HSBC) survey. For reference 1: 1= adolescent age range: 14-19 years, mean age: M 16.7 years, F 16.5 years; $2=$ study from the larger Arab Teens

Lifestyle Study. For reference 17: 1= TV-viewing categories: infrequent, frequent, and moderate viewing behaviours.

Reference numbers: (1) Al-Hazzaa et al., 2011, (2) Al-Hazzaa et al., 2013 (3) Arora et al., 2012 (4) Ciccone et al., 2013 (5) Cuenca-Garci'a et al., 2013 (6) del

Mar Bibiloni et al., 2011 (7) Fernandes et al., 2011, (8) Lee et al., 2013 (9) Honkala et al., 2012 (10) Huffman et al., 2012 (11) Ranjit et al., 2010 (12)

Santaliestra-Pasias et al., 2012 (13) Shi and Mao, 2010 (14) Sisson et al., 2012 (15) Verzeletti et al., 2010 (16) Williams and Mummery, 2012 (17) Tucker and

Tucker, 2011 
Table 3. Associations between sedentary behaviour and diet in pre-schoolchildren (aged $<5$ years)

\begin{tabular}{|c|c|c|c|c|c|}
\hline \multirow[b]{2}{*}{ Dietary behaviour } & \multirow[b]{2}{*}{$\begin{array}{c}\text { No. of } \\
\text { samples }\end{array}$} & \multicolumn{4}{|c|}{ Summary ( $n$ samples [references]) } \\
\hline & & Positive association $(+)$ & Inverse association (-) & & No association (0) \\
\hline Fruit and Vegetable (FV) & 1 & $1\left[\right.$ Cox et al. $\left.2012^{\mathrm{N}}\right]$ & $\begin{array}{l}1 \text { [Cox et al. } \\
2012^{\mathrm{L}, \mathrm{M}, \mathrm{O}, \mathrm{P}, \mathrm{Q}} \text { ] }\end{array}$ & 0 & \\
\hline Energy-dense food & 2 & $\begin{array}{l}\text { 1, } 3 \text { [Brown et al. 2010, } \\
\text { Cox et al. } \\
\left.2012^{\mathrm{L}, \mathrm{M}, \mathrm{N}, \mathrm{O}, \mathrm{P}, \mathrm{Q}}\right]\end{array}$ & 0 & 0 & \\
\hline Vegetable & 1 & 0 & $\begin{array}{l}1 \text { [Cox et al. } \\
2012^{\mathrm{L}, \mathrm{M}, \mathrm{N}, \mathrm{O}, \mathrm{P}, \mathrm{Q}} \text { ] }\end{array}$ & 0 & \\
\hline Fast Food & 1 & $\begin{array}{l}1 \text { [Cox et al. } \\
2012^{\mathrm{L}, \mathrm{M}, \mathrm{N}, \mathrm{O}, \mathrm{P}, \mathrm{Q}} \text { ] }\end{array}$ & 0 & 0 & \\
\hline Healthy Eating Index & 1 & 0 & $\begin{array}{l}1 \text { [Sisson et al. } \\
2012^{\mathrm{C}, \mathrm{B}} \text { ] }\end{array}$ & 0 & \\
\hline
\end{tabular}

For reference 4: ${ }^{\mathrm{a}}$ Objectively assessed sedentary activity using accelerometer, ${ }^{\mathrm{b}}$ Assessed using screen time questionnaire; for

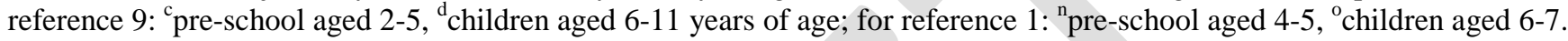

Note: All associations with dietary behaviours are with TV-viewing unless otherwise stated.

A. If in one study, dietary behaviour is examined in relation to two or more sedentary behaviours (e.g. a positive [+] association was found for studying and an inverse [-] association was found for TV and computer use), the study is counted once in the "No. of samples" column and twice in the "Summary" column.

B. Females only

C. Males only;

D. Males and females analysed separately,

E. Objectively assessed sedentary activity using accelerometer

F. Homework,

G. Separate measures of TV, computer use, internet use, internet for study, video games and studying.

$\mathrm{H}$. Separate measures of TV and computer use

I. Separate measure of TV, computer use and video

J. Screen time (TV + DVD)

K. Screen time (TV + video games + computer use + internet)

L. Non-commercial TV weekday,

M. Non-commercial TV weekend day,

N. Commercial TV weekday,

O. Commercial TV weekend day,

P. TV weekday,

Q. TV weekend

R. Computer use (games or general use) 
Table 4. Associations between sedentary behaviour and diet in school age children (aged $\geq 5-11$ years)

\begin{tabular}{|c|c|c|c|c|}
\hline \multirow[b]{2}{*}{ Dietary behaviour } & \multirow[b]{2}{*}{$\begin{array}{l}\text { No. of } \\
\text { samples }\end{array}$} & \multicolumn{3}{|c|}{ Summary ( $n$ samples [references]) } \\
\hline & & Positive association (+) & Inverse association (-) & No association (0) \\
\hline Energy-dense food & 5 & $\begin{array}{l}5 \text { [Brown et al. 2010, } \\
\text { Brown et al. 2011, } \\
\text { Gebremariam et al. } \\
2013^{(\mathrm{R}, J)} \text {, McCormack } \\
\text { et al. 2011, Ouwens et } \\
\text { al. 2012] }\end{array}$ & $\begin{array}{l}1 \text { [McCormack et al. } \\
2011^{\mathrm{R}} \text { ] }\end{array}$ & 0 \\
\hline Vegetable & 2 & $\begin{array}{l}1 \text { [McCormack et al. } \\
\left.2011^{\mathrm{R}}\right]\end{array}$ & $\begin{array}{l}2 \text { [Gebremariam et al. } \\
2013^{\mathrm{R}, J}, \text { McCormack } \\
\left.\text { et al. } 2011^{\mathrm{J}}\right]\end{array}$ & 0 \\
\hline Fat intake & 1 & $\begin{array}{l}1 \text { [Danielson et al. } \\
2011^{\mathrm{a}, \mathrm{b}} \text { ] }\end{array}$ & 0 & 0 \\
\hline Sugar intake & 1 & $\begin{array}{l}1 \text { [Danielson et al. } \\
\left.2011^{\mathrm{a}, \mathrm{b}}\right]\end{array}$ & 0 & 0 \\
\hline Total calorie intake & 1 & $\begin{array}{l}1 \text { [Danielson et al. } \\
\left.2011^{\mathrm{a},}\right]\end{array}$ & 0 & 0 \\
\hline $\begin{array}{l}\text { Diet quality (based on fat and } \\
\text { sugar) }\end{array}$ & 1 & 1 [Fuller et al. 2012] & 0 & 0 \\
\hline Fruit & 2 & 0 & $\begin{array}{l}2 \text { [Gebremariam et al. } \\
2013^{\mathrm{R}, \mathrm{J}}, \text { McCormack } \\
\text { et al. } 2011^{\mathrm{J}} \text { ] }\end{array}$ & 1 [McCormack et al. $2011^{\mathrm{R}}$ ] \\
\hline Sugar sweetened beverages & 2 & $\begin{array}{l}2 \text { [Gebremariam et al. } \\
2013^{\mathrm{R}, \mathrm{J}}, \text { McCormack et } \\
\left.\text { al. } 2011^{\mathrm{R}, \mathrm{J}}\right]\end{array}$ & 0 & 0 \\
\hline Healthy eating index & 2 & $\begin{array}{l}1 \text { [Seghers and Rutten } \\
2010^{\mathrm{F}} \text { ] }\end{array}$ & $\begin{array}{l}2 \text { [Sisson et al. } \\
2012^{\mathrm{C}, \mathrm{B}} \text {, Seghers and } \\
\text { Rutten } 2010^{\mathrm{R}} \text { ] }\end{array}$ & 0 \\
\hline $\begin{array}{l}\text { For reference } 4:{ }^{\text {a }} \text { Objectively as } \\
\text { reference 9: "pre-school aged } 2 \\
\text { Note: All associations with die } \\
\text { A. If in one study, dietary beha } \\
\text { was found for studying and an } \\
\text { "No. of samples" column and t } \\
\text { B. Females only } \\
\text { C. Males only; } \\
\text { D. Males and females analysed } \\
\text { E. Objectively assessed sedenta } \\
\text { F. Homework, } \\
\text { G. Separate measures of TV, c } \\
\text { H. Separate measures of TV an } \\
\text { I. Separate measure of TV, con } \\
\text { J. Screen time (TV + DVD) } \\
\text { K. Screen time (TV + video ga } \\
\text { L. Non-commercial TV weekd } \\
\text { M. Non-commercial TV weeke } \\
\text { N. Commercial TV weekday, } \\
\text { O. Commercial TV weekend d } \\
\text { P. TV weekday, } \\
\text { Q. TV weekend } \\
\text { R. Computer use (games or ger }\end{array}$ & $\begin{array}{l}\text { ssed sede } \\
\text { d children } \\
\text { y behavio } \\
\text { bur is exar } \\
\text { erse [-] as } \\
\text { ce in the c } \\
\text { parately, } \\
\text { activity u } \\
\text { puter use, } \\
\text { computer } \\
\text { ater use ar } \\
\text { + comp } \\
\text { day, }\end{array}$ & $\begin{array}{l}\text { ary activity using accelero } \\
\text { ged 6-11 years of age; for } \\
\text { s are with TV-viewing un } \\
\text { ned in relation to two or n } \\
\text { ociation was found for TV } \\
\text { ummary” column. } \\
\text { ng accelerometer } \\
\text { ternet use, internet for stu } \\
\text { e } \\
\text { video } \\
\text { er use + internet) }\end{array}$ & $\begin{array}{l}\text { neter, }{ }^{\mathrm{b}} \text { Assessed using sc } \\
\text { eference 1: "pre-school a } \\
\text { ss otherwise stated. } \\
\text { pre sedentary behaviours } \\
\text { and computer use), the st } \\
\text { ly, video games and stud }\end{array}$ & $\begin{array}{l}\text { een time questionnaire; for } \\
\text { ed } 4-5 \text {, }^{\circ} \text { children aged } 6-7 \text {. } \\
\text { (e.g. a positive }[+] \text { association } \\
\text { idy is counted once in the } \\
\text { ing. }\end{array}$ \\
\hline
\end{tabular}




\begin{tabular}{|c|c|c|c|c|}
\hline $\begin{array}{c}\text { Dietary } \\
\text { behaviour }\end{array}$ & $\begin{array}{c}\text { No. of } \\
\text { samples }\end{array}$ & $\begin{array}{c}\text { Positive } \\
\text { association }(+)\end{array}$ & $\begin{array}{c}\text { Inverse } \\
\text { association (-) }\end{array}$ & $\begin{array}{c}\text { No } \\
\text { association (0) }\end{array}$ \\
\hline Fruit & 3 & $1\left[\right.$ Santaliestra-Pasias $\left.{ }^{\mathrm{A}, \mathrm{G}, \mathrm{D}}\right]$ & $\begin{array}{l}\text { 5[Santaliestra-Pasias }{ }^{\mathrm{A}, \mathrm{G}, \mathrm{D}} \text {, Verzeletti }{ }^{\mathrm{S}} \text {, Al- } \\
\text { Hazza }(2011)^{\mathrm{H}, \mathrm{S}} \text {, Ciccone, Al-Hazzaa } \\
(2013)]\end{array}$ & 0 \\
\hline Vegetables & 3 & $1\left[\right.$ Santaliestra-Pasias $\left.{ }^{\mathrm{A}, \mathrm{G}, \mathrm{D}}\right]$ & $\begin{array}{l}5\left[\text { Santaliestra-Pasias }{ }^{\mathrm{A}, \mathrm{G}, \mathrm{D}} \text {, Verzeletti }{ }^{\mathrm{S}} \text {, Al- }\right. \\
\text { Hazza }(2011)^{\mathrm{H}, \mathrm{S}} \text {, Ciccone, Al-Hazzaa } \\
(2013)]\end{array}$ & 0 \\
\hline $\begin{array}{l}\text { FV (composite measure of fruit and } \\
\text { vegetables) }\end{array}$ & 1 & 0 & $1\left[\mathrm{Shi}^{\mathrm{H}, \mathrm{S}}\right]$ & 0 \\
\hline Juices & 1 & $1\left[\right.$ Santaliestra-Pasias $\left.{ }^{\mathrm{A}, \mathrm{G}, \mathrm{D}}\right]$ & $1\left[\right.$ Santaliestra-Pasias $\left.{ }^{\mathrm{A}, \mathrm{G}, \mathrm{D}}\right]$ & 0 \\
\hline Savoury snacks & 1 & 1 [Santaliestra-Pasias $\left.{ }^{\mathrm{A}, \mathrm{G}, \mathrm{D}}\right]$ & 1 [Santaliestra-Pasias $\left.{ }^{\mathrm{A}, \mathrm{G}, \mathrm{D}}\right]$ & 0 \\
\hline Fast food & 4 & [Shi ${ }^{\mathrm{H}, \mathrm{S}} \mathrm{Al}-H a z z a(2011)^{\mathrm{H}, \mathrm{S}}$ Lee, Al-Hazzaa(2013)] & 0 & 0 \\
\hline Fried foods & 2 & $2\left[\right.$ Fernandes $\left.{ }^{\mathrm{S}} \mathrm{Al}-\mathrm{Hazza}(2011)^{\mathrm{H}, \mathrm{S}}\right]$ & 0 & 0 \\
\hline High-sugar foods & 1 & $1\left[\right.$ Shi $\left.^{\mathrm{H}, \mathrm{S}}\right]$ & 0 & 0 \\
\hline Western dietary pattern & 1 & 2[del Mar Bibiloni ${ }^{\mathrm{D}}$, Lee] & 0 & 0 \\
\hline Mediterranean dietary pattern & 1 & 0 & 1[del Mar Bibiloni $\left.{ }^{\mathrm{D}}\right]$ & 0 \\
\hline Breakfast consumption & 2 & 1 [Arora $\left.^{\mathrm{S}, \mathrm{T}}\right]$ & 2[Al-Hazza $(2011)^{\mathrm{H}, \mathrm{S}}$, Cuenca-Garcia] & 1 [Arora $^{\mathrm{A}, \mathrm{H}, \mathrm{S}}$ ] \\
\hline $\begin{array}{l}\text { Healthy food index score/Healthy } \\
\text { nutrition behaviours }\end{array}$ & 2 & $1\left[\right.$ Williams $\left.{ }^{\text {A,D,U }}\right]$ & 2 Sisson $^{\mathrm{D}}$, Williams $\left.{ }^{\mathrm{A}, \mathrm{G}, \mathrm{D}}\right]$ & 0 \\
\hline Milk/dairy & 2 & 1 [Santaliestra-Pasias ${ }^{\mathrm{A}, \mathrm{G}, \mathrm{D}}$ ] & $\begin{array}{l}3\left[\operatorname{Sisson}^{\mathrm{A}, \mathrm{G}, \mathrm{D}}, \mathrm{Al}-\operatorname{Hazza}(2011)^{\mathrm{H}, \mathrm{S}}, \mathrm{Al}-\right. \\
\text { Hazzaa (2013)] }\end{array}$ & 0 \\
\hline Desserts & 1 & 1 [Santaliestra-Pasias $^{\mathrm{A}, \mathrm{G}, \mathrm{D}}$ ] & $1\left[\right.$ Sisson $\left.^{\mathrm{A}, \mathrm{G}, \mathrm{D}}\right]$ & \\
\hline Cakes & 2 & [Santaliestra-Pasias A,G,D Al-Hazza (2011) ${ }^{\mathrm{H}, \mathrm{S}}$ ] & $1\left[\right.$ Sisson $\left.^{\mathrm{A}, \mathrm{G}, \mathrm{D}}\right]$ & 0 \\
\hline Sweets & 2 & [Honkala ${ }^{\mathrm{S}}$, Al-Hazza $(2011)^{\mathrm{H}, \mathrm{S}}$ ] & & 0 \\
\hline Energy drinks & 2 & [Al-Hazza (2011) $\left.{ }^{\mathrm{H}, \mathrm{S}}, \mathrm{Al}-\mathrm{Hazzaa}(2013)\right]$ & & 0 \\
\hline Sugar sweetened beverages & 6 & $\begin{array}{l}5 \text { [Honkala }^{\mathrm{S}} \text {, Santaliestra-Pasias }{ }^{\mathrm{A}, \mathrm{G}, \mathrm{D}}, \text { Shi }^{\mathrm{H}, \mathrm{S}} \text {, Al-Hazzaa } \\
(2011)^{\mathrm{H}, \mathrm{S}}{ }^{\text {, Ranjit }}{ }^{\mathrm{D}} \text {, Al-Hazzaa (2013)] }\end{array}$ & $1\left[{ }^{\text {Sisson A,G,D }}\right]$ & 0 \\
\hline Korean health dietary pattern & 1 & Lee & 0 & \\
\hline
\end{tabular}

Note: All associations with dietary behaviours are with TV-viewing unless otherwise stated. For reference Honkala: younger cohort (mean age 13 years). For reference

Fernandes: only 'TV-viewing (high frequency)' data given, mean age 13.8B and 13.9G. For reference Arora: adolescents in grades 8-10. For reference Shi: adolescents mean age 14.4. For reference Williams: adolescents in school years 9-12. For reference Verzeletti: adolescents aged 11-16 years, and part of the larger Health Behaviour in SchoolAged Children study examining associations between TV-viewing and diet. For reference Ranjit: adolescents in grades 8 and 11. For reference Al-Hazza (2011): older cohort (age 14-19 years). For reference Santaliestra-Pasias: adolescents aged 12.5 - 17.5 years. 
Table 6. Associations between sedentary behaviour and diet in adults (aged $>18$ years)

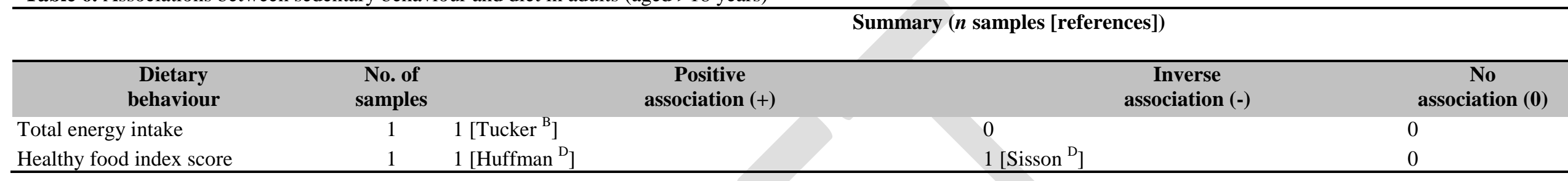

Note: All associations with dietary behaviours are with TV-viewing unless otherwise stated. For Tucker reference: TV-viewing categorised as infrequent, moderate, and frequent viewing. For Huffman reference: only 'high TV-viewing' data given.

A. If in one study, dietary behaviour is examined in relation to two or more sedentary behaviours (e.g. a positive [+] association was found for studying and an inverse [-] association was found for TV and computer use), the study is counted once in the "No. of samples" column and twice in the "Summary" column.

B. Females only

C. Males only;

D. Males and females analysed separately,

E. Objectively assessed sedentary activity using accelerometer

F. Homework,

G. Separate measures of TV, computer use, internet use, internet for study, video games and studying.

H. Separate measures of TV and computer use

I. Separate measure of TV, computer use and video

J. Screen time (TV + DVD)

K. Screen time (TV + video games + computer use + internet

L. Non-commercial TV weekday,

M. Non-commercial TV weekend day,

N. Commercial TV weekday,

O. Commercial TV weekend day,

P. TV weekday,

Q. TV weekend

R. Computer use (games or general use)

S. Males and females analysed together

T. SB measure of studying for weekday and weekend.

U. Sedentary education time (reading + homework) 